An analysis of public policy issues and how they affect MRS members and the materials community...

\title{
How Materials Researchers Can Invest in Future Science and Technology Politics
}

In light of the ever-changing dynamics in the U.S. Congress and the Presidential Administration and the efforts to balance the federal budget, the materials community needs to carefully examine how its involvement in the political process can help shape future policies in science and engineering education and in federal funding of research and development (R\&D) programs. Participating in the political process are critical for two reasons. First, science and technology policies are receiving much attention due to the transformation of research focus from defense to civilian R\&D. Second, all discretionary federal funding levels--of which science is part-are diminishing due to the focus on balancing the budget. Though the short- and long-term political impact on the materials community may be unclear, this article will describe strate- gies that materials researchers can implement to help weave the materials community perspective into the future needs of the country.

Legislators and policymakers are keen on serving and representing the views of their constituents to the best of their ability. Lawmakers operate typically as generalists and look to their community for expertise in many areas as they explore issues, policies, and laws. Relationshipbuilding is the keystone of forging an effective dialogue with any congressional representative. Developing long-standing relationships built on trust, mutual respect, open communication, and enthusiasm in serving as a resource for the legislator will reap benefits for the materials community. Rather than writing letters of complaint, the role of a materials scientist is to inform the legislator on how a scien- tific issue or program affects her or his state's economy, for example, or society as a whole. Advocates provide the substance and the legislators decide how to get ideas and laws accepted by their peers. Materials researchers can engage legislators by setting up a meeting in their home districts or inviting them to the laboratory for a site visit to foster an understanding of the outcome of the research and development, and to exhibit how the laboratory benefits the local community in terms of jobs, outreach, or education. Bringing key science- and technologyrelated issues onto the legislators' radar screen in annual doses will prompt them to be more alert to the materials community's concerns when science-related legislation is offered in committees or on the House or Senate floor.

The Materials Research Society can

\section{The New Age of $x-$ ray Microanalysis is here... the Age of Sapphire.}

\author{
The Age of: \\ * The best standard resolution of any EDS detector \\ * Sapphire reliability backed by a three-year warranty \\ * Optimum sensitivity with 20,000:1 peak-to-background ratio
}

Now leading in advanced detector technology, EDAX developed the Sapphire detectors for the 21st century, with performance standards beyond your expectations and as an instrument to help provide solutions to all your $\mathrm{x}$-ray microanalysis problems.

With the Sapphire detectors you can do it all, without having to make compromises. It's a new age in $\mathrm{x}$-ray microanalysis... the Age of Sapphire. Call EDAX today.

Sapphire. A Shining Example of Peak Performance.

\section{Visit MRS Exhibit} Booth No. U405

91 Mckee Drive Mahwah, NJ 07430-9978 Tel. Office: $201-529-4880$ Fax: 201-529-3156
Ringbaan Noord 103, P.O. Box 4144 5004 JC Tilburg. The Netherlands Tel. Office: +31-13-5364000 Fax: $+31-13-5356279$
13-37, Kohnan 2-chome, Minato-ku Tokyo 108, Japan

Tel. Office: 81-3-3740-5172

Fax: 81-3-3740-5190

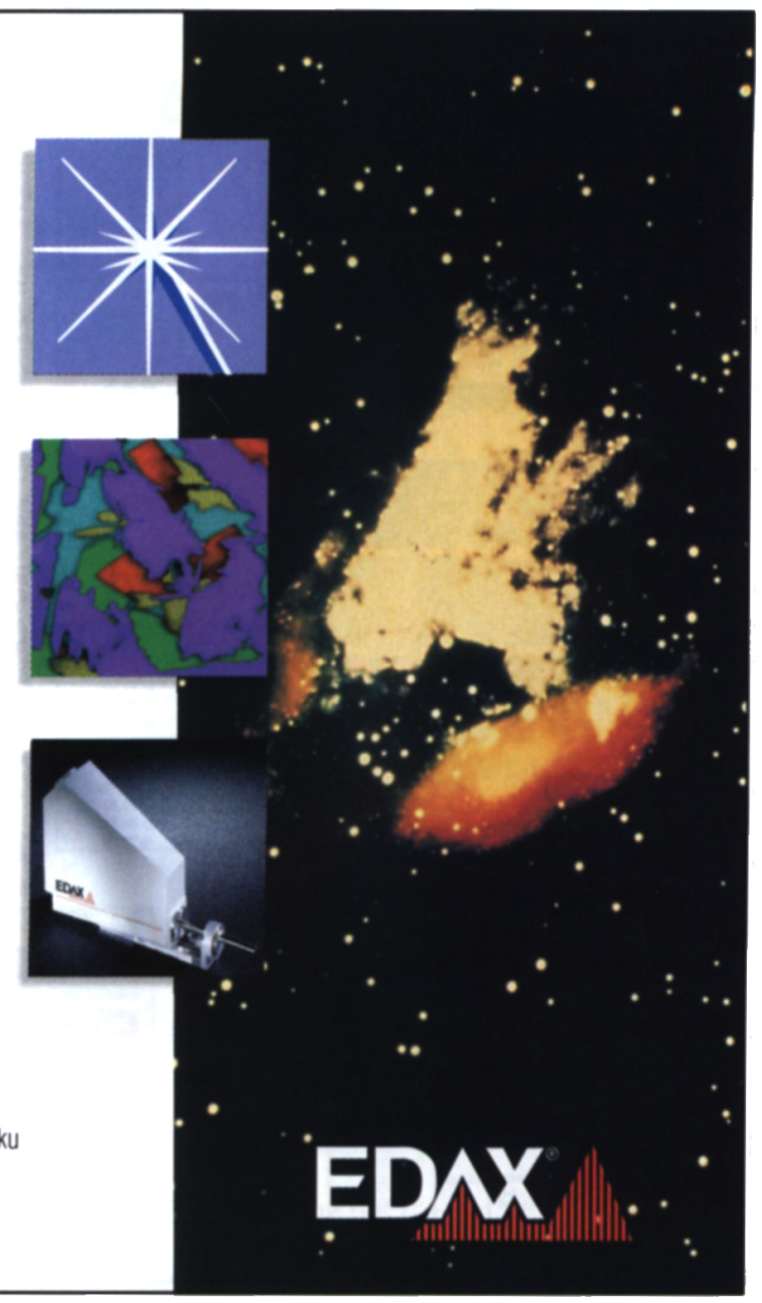


motivate increased dialogue and understanding between the materials community and congressional members and their staff. Many creative and effective mechanisms can be designed to reach MRS members at all levels. The vehicles are already in place: MRS Bulletin, the MRS Website, biannual meetings, and district and university chapter meetings. Implementing such resources helps to mobilize the materials community to support global ideas on science and technology.

These venues provide a conduit for educating MRS members on effective ways to grab legislators' attention, for alerting MRS members on current legislative activity which would be of professional interest to them, and for disseminating relevant resources and useful tools that MRS members could use when meeting with legislators. The July 1996 issue of MRS Bulletin announced the release of a Department of Commerce report entitled,
"Federal Research and Development Program in Materials Science and Technology" (http:/ / www.doe.gov/doe/ whatsnew/reports.html), which could be used as an effective platform for organizing workshops and visits to legislators. Working in concert with other professional societies to develop resources for its members can reduce the workload and also build an invaluable network.

Immersing scientists in the congressional arena is yet another mode of expanding a mutual understanding between science and politics. The materials and optics community took a very bold step in sponsoring a Congressional Fellow to work with a member of Congress. Materials Research Society/Optical Society of America Congressional Fellows learn about the inner workings of Congress and the resolution of scientific issues while acting as technical and scientific resources for science and technology-related policy decisions.
MRS/OSA Congressional Fellows can share their insights and experiences with the materials community.

Being science activists does not mean scientists must immerse themselves in partisan politics. Science has an essential role in government, and only through cooperation and communication can materials scientists provide the most sound basis for leading the U.S. government through these important times. Investments in laying the groundwork to advocate science and technology to Congress are critical to the materials community and to the general public.

KELLY S. KiRKPATRICK

Kelly S. Kirkpatrick is the first Materials Research Society/Optical Society of America Congressional Fellow. She served Senator Joseph I. Lieberman (D-CT) on a wide range of science- and techology-related issues. She can be reached by e-mail atkkdk@charm.net.

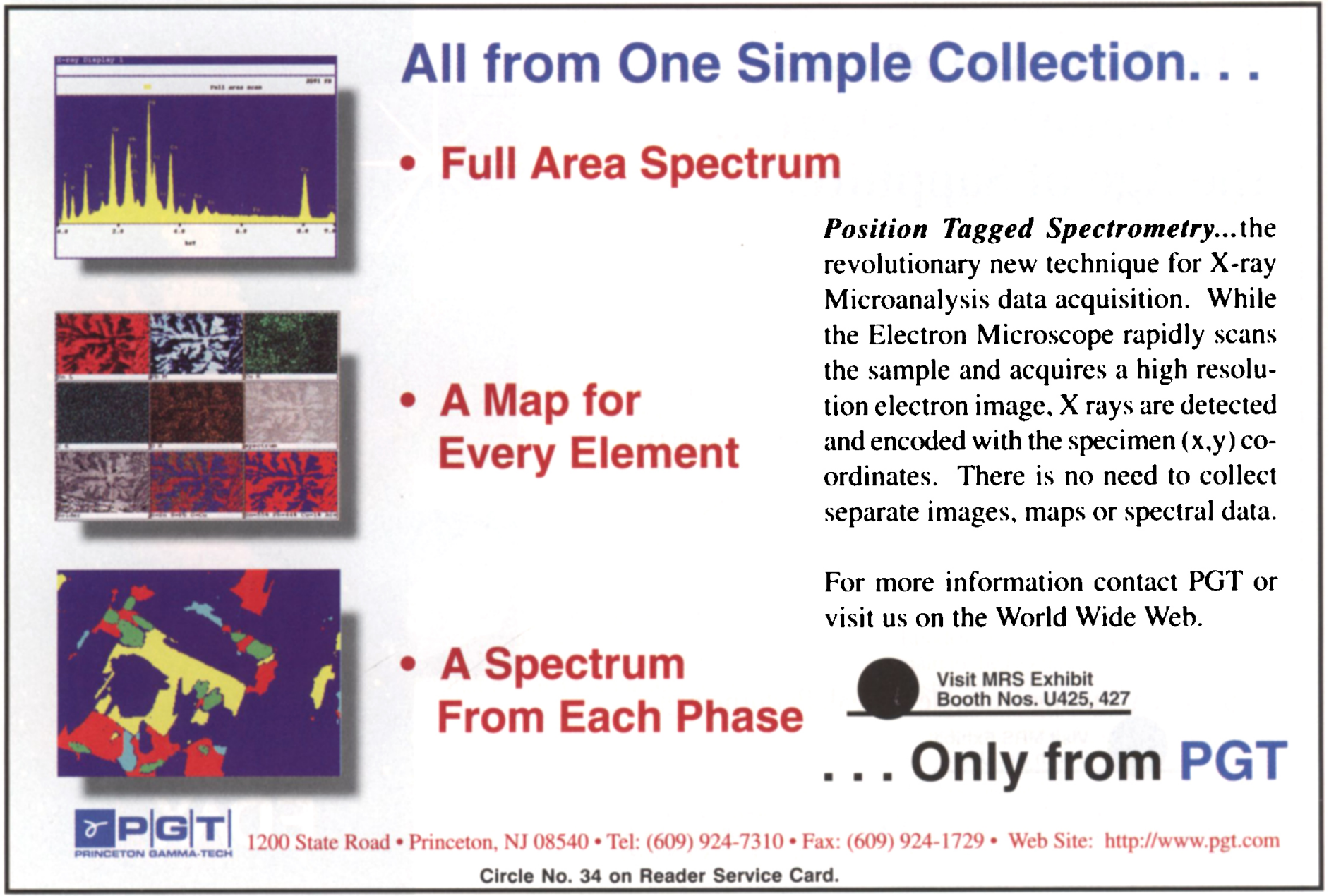

